\title{
Regression of orthotopic neuroblastoma in mice by targeting the endothelial and tumor cell compartments Dieter Fuchs*1, Rolf Christofferson ${ }^{1,2}$, Mats Stridsberg 3 , Elin Lindhagen ${ }^{3}$ and Faranak Azarbayjani ${ }^{1}$
}

\author{
Address: ${ }^{1}$ Department of Medical Cell Biology, Uppsala University, 75123 Uppsala, Sweden, ${ }^{2}$ Department of Woman and Child Health, Uppsala \\ University Hospital, 75185 Uppsala, Sweden and ${ }^{3}$ Department of Medical Sciences, Uppsala University Hospital, 75185 Uppsala, Sweden \\ Email: Dieter Fuchs* - dieter.fuchs@mcb.uu.se; Rolf Christofferson - rolf.christofferson@kbh.uu.se; \\ Mats Stridsberg - mats.stridsberg@medsci.uu.se; Elin Lindhagen - elin.lindhagen@medsci.uu.se; \\ Faranak Azarbayjani - faranak.azarbayjani@mcb.uu.se \\ * Corresponding author
}

Published: 12 March 2009

Journal of Translational Medicine 2009, 7:16 doi:10.1 186/1479-5876-7-16
Received: 29 September 2008

Accepted: 12 March 2009

This article is available from: http://www.translational-medicine.com/content/7/1/16

(C) 2009 Fuchs et al; licensee BioMed Central Ltd.

This is an Open Access article distributed under the terms of the Creative Commons Attribution License (http://creativecommons.org/licenses/by/2.0), which permits unrestricted use, distribution, and reproduction in any medium, provided the original work is properly cited.

\begin{abstract}
Background: High-risk neuroblastoma has an overall five-year survival of less than $40 \%$, indicating a need for new treatment strategies such as angiogenesis inhibition. Recent studies have shown that chemotherapeutic drugs can inhibit angiogenesis if administered in a continuous schedule. The aim of this study was primarily to characterize tumor spread in an orthotopic, metastatic model for aggressive, MYCN-amplified neuroblastoma and secondarily to study the effects of daily administration of the chemotherapeutic agent CHS 828 on tumor angiogenesis, tumor growth, and spread.
\end{abstract}

Methods: MYCN-amplified human neuroblastoma cells (IMR-32, $\left.2 \times 10^{6}\right)$ were injected into the left adrenal gland in SCID mice through a flank incision. Nine weeks later, a new laparotomy was performed to confirm tumor establishment and to estimate tumor volume. Animals were randomized to either treatment with CHS $828(20 \mathrm{mg} / \mathrm{kg} / \mathrm{day}$; p.o.) or vehicle control. Differences between groups in tumor volume were analyzed by Mann-Whitney $U$ test and in metastatic spread using Fisher's exact test. Differences with $\mathrm{p}<0.05$ were considered statistically significant.

Results: The orthotopic model resembled clinical neuroblastoma in respect to tumor site, growth and spread. Treatment with CHS 828 resulted in tumor regression $(\mathrm{p}<0.00 \mathrm{I})$ and reduction in viable tumor fraction $(p<0.001)$ and metastatic spread $(p<0.05)$ in correlation with reduced plasma levels of the putative tumor marker chromogranin $A(p<0.001)$. These effects were due to increased tumor cell death and reduced angiogenesis. No treatment-related toxicities were observed.

Conclusion: The metastatic animal model in this study resembled clinical neuroblastoma and is therefore clinically relevant for examining new treatment strategies for this malignancy. Our results indicate that daily scheduling of CHS 828 may be beneficial in treating patients with high-risk neuroblastoma. 


\section{Background}

Neuroblastoma (NB) is the most common extracranial solid tumor of childhood. High-risk NB has a long-term survival rate of less than $40 \%$ despite intensive treatment protocols involving high-dose chemotherapy, usually with bone marrow rescue, aggressive surgery, and radiotherapy $[1,2]$. Therefore, new treatment strategies, evaluated in clinically relevant, reliable, and reproducible animal models, are needed for this malignancy.

Angiogenesis inhibition is a novel treatment strategy, where the formation of new blood vessels is inhibited, thereby reducing both the metabolic exchange of the tumor and its vascular access for metastatic spread. In NB, a high tumor angiogenesis correlates with metastatic disease and poor outcome [3]. Furthermore, increased microvascular proliferation has recently been shown to correlate with poor survival in children with NB [4]. There are many ways for angiogenesis inhibition, e.g. specific inhibition of an angiogenic growth factor. In s.c. models for NB, this approach resulted in a significantly reduced tumor growth rate $[5,6]$. Another way for angiogenesis inhibition is based on modified schedules and doses of chemotherapeutic drugs, namely, switching from the current maximum tolerable dose (MTD) to a continuous dosing scheme [7]. Even though endothelial cells are damaged by MTD, the beneficial antiangiogenic effects of MTD schedules are compromised by treatment breaks between cycles. These breaks are required for patient recovery but allow endothelial cell repair and regrowth $[8,9]$. Chemotherapy given at frequent intervals without extended rest periods, has been shown to target endothelial cells and tumor vessels in vivo [10]. The benefits of continuous therapy, e.g. reduced host toxicity together with continuous drug exposure resulting in a sustained antiangiogenic effect, are investigated in a number of clinical trials [11].

The chemotherapeutic drug CHS 828 is a pyridylguanidine that potently inhibits nicotinamide phosphoribosyl transferase (NAMPT) in a time dependent manner $[12,13]$. NAMPT is an enzyme involved in the biosynthesis of oxidized nicotinamide adenine dinucleotide $\left(\mathrm{NAD}^{+}\right)$. In eukaryotic cells NAD ${ }^{+}$has been shown to play a pivotal role as an essential coenzyme/transmitter molecule for the generation of ATP. Due to the higher proliferation rate, cancer cells demand higher ATP synthesis and therefore have higher turnover of $\mathrm{NAD}^{+}$and an upregulated NAMPT enzyme to meet this energy demand. In fact, NAMPT inhibition with CHS 828 has shown significant antitumor activity in many preclinical in vitro and in vivo models [14-17]. In clinical phase I studies conducted with CHS 828, doses up to $500 \mathrm{mg}$ were administered to patients. Based on the observed dose limiting toxicities at $500 \mathrm{mg}\left(228 \mathrm{mg} / \mathrm{m}^{2}\right)$, Ravaud et al. suggested administra- tion of 420 mg CHS 828 every 3 weeks for clinical phase II studies [18] whereas the results of another clinical phase I study recommended more frequent administration at 20 mg once a day for 5 days in cycles of 28 days duration [19].

In preclinical studies in mice, CHS 828 could reduce growth of s.c. NB without any signs of toxicity [17]. In order to investigate this finding in a clinically more relevant setting, we developed and characterized a relevant orthotopic mouse models for high-risk NB. Generally, orthotopic tumor models resemble clinical disseminated disease more closely and have a more realistic tumor-host interaction than heterotopic, s.c. models. To be able to evaluate and to make a direct comparison between these models in treating NB, mice bearing orthotopic tumors were treated with the same dose and route of administration as in [17].

We found that the orthotopic growth and spread of NB cells in SCID mice resembled the patterns observed in high-risk NB patients. Daily oral administration of a nontoxic dose of CHS 828 to the host animal induced tumor regression and reduced bone marrow and liver metastases by a dual mechanism of action, restraining growth of both tumor cells and tumor vasculature.

\section{Methods \\ CHS 828}

The chemotherapeutic drug CHS 828 (N-(6-chlorophenoxyhexyl)-N'-cyano-N"-4-pyridylguanidine) was supplied by LEO Pharma (Ballerup, Denmark). For in vitro use, CHS 828 was dissolved to $5 \mathrm{mM}$ in dimethyl sulfoxide (DMSO) (Merck, Darmstadt, Germany) and further diluted in serum-free culture medium. For the in vivo study, the drug was suspended in peanut oil $(5 \mu \mathrm{g} / \mu \mathrm{l})$ at least once a week and stored at $4-8^{\circ} \mathrm{C}$.

\section{Cells}

The human NB cell line IMR-32 (ATCC, Rockville, MD), isolated from an abdominal NB in a 13-month-old boy, is MYCN amplified and has a $1 \mathrm{p}$ deletion and a $47+\mathrm{XY}$ karyotype [20]. SH-SY5Y (kindly provided by Dr. June Biedler, The Memorial Sloan-Kettering Cancer Centre, $\mathrm{NY}$ ) was derived from a poorly differentiated, nonMYCN-amplified human NB [21]. SK-N-SH, a kind gift of Dr. Fredrik Hedborg, Uppsala University, Sweden, was isolated from a bone marrow metastasis of a 4 year old female NB patient. Cells were cultured as described previously [5]. Non-essential amino acids (Sigma Chemical Co., St. Louis, MO) were added to IMR-32 cells. Human foreskin fibroblasts (CCD-1064SK, a kind gift of Dr. Magnus Essand, Uppsala University, Sweden) were cultured under the same conditions as SH-SY5Y [5]. Immortalized bovine endothelial cells (hTERT-BCE [22], a kind gift 
from Dr. Yihai Cao, Karolinska Institute, Stockholm, Sweden), were cultured as described previously [22].

All cells tested negative for mycoplasms and were grown in humidified air $(95 \%)$ and $5 \% \mathrm{CO}_{2}$ at $37^{\circ} \mathrm{C}$. All in vitro experiments were performed under optimal culture conditions (i.e. with serum).

\section{Fluorometric microculture cytotoxicity assay}

Drug cytotoxicity was determined using the fluorometric microculture cytotoxicity assay (FMCA) method [23]. Briefly, CHS 828 stock solution, dissolved to $5 \mathrm{mM}$ in DMSO, was diluted in medium to final concentrations ranging from $0.1 \mathrm{nM}$ to $10 \mu \mathrm{M}$. Triplicates of drug solutions $(10 \times$ final concentration; $20 \mu \mathrm{l})$ were added to $\mathrm{v}$ bottomed 96-well microtiter plates (Nunc, Roskilde, Denmark). NB cells $(20,000 /$ well $)$, fibroblasts $(15,000 /$ well $)$ and endothelial cells (5,000/well) (cultured in medium containing $10 \%$ serum) were added to the wells, and the cell survival index, defined as fluorescence in percent of control cultures, was calculated after a 24,48 , and $72 \mathrm{~h}$ incubation period. $\mathrm{IC}_{50}$ values were determined as $\mathrm{CHS}$ 828 concentrations with a survival index below $50 \%$.

\section{Cell morphology and cell death in vitro}

Morphological changes in NB cells due to exposure to CHS 828 were assessed by phase-contrast microscopy. IMR-32 $\left(1.5 \times 10^{5} / \mathrm{ml}\right)$ were allowed to set overnight before replacing the medium with fresh medium containing $1 \mathrm{nM}$ CHS 828. The cell morphology was recorded after $0,4,24,48,72$, and $96 \mathrm{~h}$ with a digital phase-contrast microscope at $\times 100$.

Quantification of cell death was performed by propidium iodine (PI) and DAPI (4',6-diamino-2-phenylindole) staining [24]. IMR-32 cells $\left(1.5 \times 10^{5} / \mathrm{ml}\right)$ were stained with $10 \mu \mathrm{g} / \mathrm{ml}$ PI and DAPI after 24, 48, and $72 \mathrm{~h}$ exposure to $1 \mathrm{nM}$ CHS 828. Disintegration of the plasma membrane results in red fluorescence, which is a marker of cell death (determined by evaluation of at least 2,000 cells per well by UV microscopy).

\section{Animals}

Female SCID mice (B\&M, Ry, Denmark) were xenografted at the age of 6 weeks (mean body weight, $17.3 \mathrm{~g}$ ). The animals were housed in an isolated room at $24^{\circ} \mathrm{C}$ with a 12 $\mathrm{h}$ day/night cycle. They were fed ad libitum with water and food pellets. Animal weight and general appearance were recorded daily throughout the experiment. The experiment was approved by the regional ethics committee for animal research.

\section{Xenografting and confirmation of tumor establishment}

Subconfluent IMR-32 cells were harvested and kept on ice until xenotransplantation. The recipient mice were shaved and cleansed with $70 \%$ ethanol at the site of incision and anesthetized with $2 \%$ Fluothane (Zeneca Ltd., Macclesfield, UK) supplemented with $50 \% \mathrm{~N}_{2} \mathrm{O}$ in oxygen. IMR32 cells $\left(20 \mu \mathrm{l} ; 2 \times 10^{6}\right.$ cells $)$ were injected into the left adrenal gland through a left flank incision, which was closed with interrupted sutures in 2 layers. Buprenorphine $(10 \mu \mathrm{g} / \mathrm{kg} ;$ s.c.; Schering-Plough Europe, Brussels, Belgium) was administered once as postoperative analgesia. All handling of the animals was performed under aseptic conditions.

Nine weeks after xenografting, all animals $(\mathrm{n}=35)$ showed establishment of primary adrenal gland tumors which was verified by re-laparotomy. Tumor volume (mean volume: $0.77 \mathrm{ml}$ ), was estimated as described in [25].

\section{Measurement of tumor volume, drug administration, perfusion fixation, and autopsy}

Mice were randomized to 1 of the 3 groups: controls (peanut oil, daily, p.o., 10 days; $\mathrm{n}=10$ ) and CHS 828 treatment $(20 \mathrm{mg} / \mathrm{kg}$, daily, p.o.) for $10(\mathrm{n}=13)$ or 30 days (n $=10$ ). Administration of $20 \mathrm{mg} / \mathrm{kg} /$ day has previously been shown to be non-toxic to mice. At the study endpoints, animals were subjected to perfusion fixation [17]. After perfusion fixation, the tumors were dissected out, and their absolute weights and volumes were recorded. The internal organs were examined for macroscopic metastases (see below).

\section{Chromogranin A analyses}

Chromogranin A (CgA) serum levels were analyzed as a marker for tumor burden and treatment efficacy. Venous blood was drawn from the right atrium before perfusion fixation. The blood was stored at $4{ }^{\circ} \mathrm{C}$ overnight and spun at $135 \times \mathrm{g}$ for $10 \mathrm{~min}$. The serum was removed and stored at $-20^{\circ} \mathrm{C}$. Serum levels of human CgA were measured by a commercial radioimmunoassay (Eurodiagnostica, Malmö, Sweden) according to the manufacturer's instructions. Only tumor-derived $\mathrm{CgA}$ was detected since the assay distinguishes between human and murine CgA.

\section{Tissue analyses}

At autopsy, the organs were examined for macroscopic metastases, sliced in $~ 1-\mathrm{mm}$ sections, and examined with a dissection microscope $(\times 20)$. Orthotopic tumors, the iliac crest, and organ biopsies with suspected metastases were dehydrated and embedded in paraffin. Tissue sections were cut at $3 \mu \mathrm{m}$, placed on diaminoalkyl-silanetreated glass slides, dewaxed, rehydrated, and stained immunohistochemically as described below. All these steps were performed in humid chambers at room temperature, unless otherwise indicated. After immunohistochemistry, the sections were counterstained with Harris' 
hematoxylin and mounted with Kaiser's glycerol gelatin (Merck).

For the quantification of angiogenesis, Bandeiraea simplicifolia-1 (BS-1) lectin was used to mark endothelial cells [25]. BS-1 (L3759; Sigma) was used at 1:50 dilution, and the sections were incubated for $2 \mathrm{~h}$. Endothelial cells were used as positive controls, and the omission of the neuraminidase solution served as a negative control.

Immunohistochemical staining for DNA strand breaks (i.e. cell death) was performed by the TUNEL assay using an "In Situ Cell Death Detection Kit, POD" (Roche, Indianapolis, IN) according to the manufacturer's instructions. Murine ileum was used as a positive control, and the replacement of TdT with water served as a negative control.

Apoptosis was detected by staining for cleaved caspase- 3 [6]. Sections were developed using Vector ${ }^{\circledast}$ NovaRED $^{\mathrm{TM}}$ (SK-4800, Vector Laboratories, Inc., Burlingame, CA). Human tonsil or murine colon served as a positive control, and the omission of the primary antibody served as a negative control.

Staining specific for neuroendocrine and adrenergic cells, i.e. NB cells, was performed by CgA immunohistochemistry. Before dehydration and embedding in paraffin, iliac crest biopsies were decalcified in Parengy's decalcification solution (University Hospital Pharmacy, Uppsala, Sweden) for 1 week. Tissue sections on glass slides were treated with Target Retrieval Solution (S3308, Dako) and blocked in $0.3 \% \mathrm{H}_{2} \mathrm{O}_{2}$ for $30 \mathrm{~min}$ and in $1 \%$ BSA and $10 \%$ rabbit serum for $20 \mathrm{~min}$. Primary antibody (M0869, Dako) was applied at 1:100 dilution for $30 \mathrm{~min}$. The biotinylated secondary antibody (K335, Dako A/S) was applied at 1:80 dilution for $30 \mathrm{~min}$. For detection, ABC/ HRP (K355, Dako) was applied at 1:100 dilution for 30 min. The sections were developed using DAB (SK-4100, Vector). NB cell pellets were used as positive controls, and the omission of the primary antibody served as a negative control. To detect NB cells in the bone marrow of the iliac crest, 3 CgA-stained sections were examined in a blinded fashion by 2 independent investigators. Two to $3 \mathrm{CgA}$ positive cells in one section were classified as metastasis.

\section{Stereologic quantification}

All sections were quantified at $\times 400$ magnification in a blinded fashion $[5,26]$. Vascular parameters from up to 35 grids, depending on tumor size, were quantified for each tumor. Only stereologic estimates from grids with a viable upper right corner and in which the entire grid covered tumor tissue were used for quantification. If more than $50 \%$ of the upper right corner covered densely packed nuclei with sparse cytoplasm (i.e. NB cells), the grid was assigned 'viable'.

The percentage of TUNEL- and caspase-3-positive cells was calculated among 2,000 cells in each tumor by using the upper right quarter of the counting grid mentioned above.

Treatment-related bone marrow toxicity was investigated in hematoxylin-eosin stained sections of the iliac crest. The percentage of megakaryocytes was calculated among at least 2,000 bone marrow cells.

\section{Statistical methods}

All the data were processed in GraphPad Prism 4 for Windows (GraphPad Software Inc.). Differences between tumor volumes were analyzed with Mann-Whitney $U$ test and differences in organ weight were analyzed using the Kruskal-Wallis test. Statistical differences between metastases in CHS 828-treated animals and control animals were analyzed using Fisher's exact test. Differences with p $<0.05$ were considered statistically significant.

\section{Results}

CHS 828 is toxic to NB cells but not to fibroblasts in vitro CHS 828 was more toxic to NB cells than to endothelial cells or fibroblasts in vitro. $\mathrm{IC}_{50}$ values for fibroblasts were above $10 \mu \mathrm{M}$ CHS 828 (the highest concentration tested). Drug activity was time dependent with the first signs of toxicity after $48 \mathrm{~h}$ and high NB cell-specific toxicity after $72 \mathrm{~h}$ of continuous drug exposure (Table 1).

IMR-32 viability remained unaffected during the first $48 \mathrm{~h}$ of exposure to $1 \mathrm{nM}$ CHS 828 but showed a $560 \%$ increase in cell death after $72 \mathrm{~h}$ of exposure as compared to controls (Figure 1A, B).

Table I: CHS 828 toxicity profile

\begin{tabular}{cccc}
\hline & & \multicolumn{1}{c}{$\mathrm{IC}_{50}$} \\
& $24 \mathrm{~h}$ & $48 \mathrm{~h}$ & $72 \mathrm{~h}$ \\
\hline \multirow{2}{*}{ htertBCE } & $>10 \mu \mathrm{M}$ & $200-500 \mathrm{nM}$ & $50-100 \mathrm{nM}$ \\
SH-SY5Y & $>10 \mu \mathrm{M}$ & $>10 \mu \mathrm{M}$ & $2-5 \mathrm{nM}$ \\
IMR-32 & $>10 \mu \mathrm{M}$ & $>10 \mu \mathrm{M}$ & $0.2-0.5 \mathrm{nM}$ \\
SK-N-SH & $>10 \mu \mathrm{M}$ & $>10 \mu \mathrm{M}$ & $2-5 \mathrm{nM}$ \\
CCD-I064SK & n.d. & n.d. & $>10 \mu \mathrm{M}$ \\
& & &
\end{tabular}

Triplicates of the NB cell lines IMR-32, SH-SY5Y, SK-N-SH cells $(I \times$ $105 / \mathrm{ml})$, human foreskin fibroblasts CCD- I064SK $\left(7.5 \times 10^{4} / \mathrm{ml}\right)$ and endothelial cells htertBCE $(2.5 \times 104 / \mathrm{ml})$ were incubated with 16 different concentrations of CHS 828 for 24,48 and $72 \mathrm{~h}$ (concentration range: $0.1 \mathrm{nM}-10 \mu \mathrm{M}$ ). Cell survival was measured by FMCA. Survival index was calculated as the percentage of viable cells at the actual concentration divided by percentage of viable cells in wells incubated without drug. Concentration intervals for $I C_{50}$. 


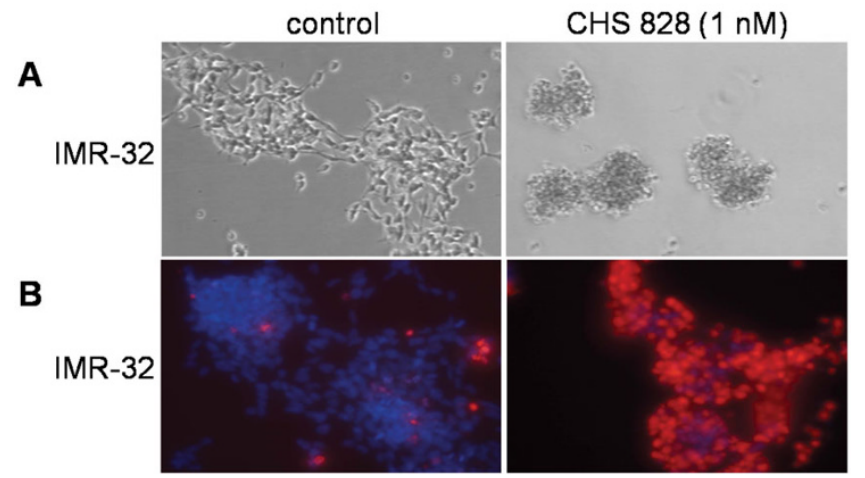

Figure I

In vitro morphology of NB cells cultured with or without CHS 828. IMR-32 $\left(I .5 \times 10^{5} / \mathrm{ml}\right)$ were cultured in 24well plates in the absence (control) or presence of I nM CHS 828 for 0 to $72 \mathrm{~h}$. Cell morphology, investigated by phasecontrast microscopy, revealed signs of cell death in NB cells exposed to CHS 828 (A). Viability of NB cells (IMR-32) was quantified in DAPI (4',6-diamino-2-phenylindole)-propidium iodine $(10 \mu \mathrm{g} / \mathrm{ml})$-stained cells by fluorescence microscopy (B). Cells with intact plasma membrane (blue; DAPI staining) and cells with disrupted membrane (red; propidium iodine staining), magnification in A-B: $\times 100$.

\section{CHS 828 induces regression of rapidly growing orthotopic NB in vivo}

Tumors from vehicle-treated animals grew significantly within 10 days from randomization $(\mathrm{p}<0.05)$ (Figure 2, Figure 3). Despite this rapid growth, no tumor rupture or intraperitoneal bleeding was observed. Daily treatment with CHS 828 (20 mg/kg; p.o.) for 10 days significantly reduced mean tumor volume $(-89 \%)$ and weight $(-92 \%)$ compared to untreated littermates $(\mathrm{p}=0.0002$ and $\mathrm{p}=$ 0.0001 , respectively). An additional 20 days of treatment (total of 30 days) further reduced tumor volume (-92\%) and weight $(-86 \%)$ compared to short term treatment ( $\mathrm{p}$ $=0.0005$ and $\mathrm{p}=0.0006$, respectively) (Figure 2, Figure $3)$. Administration of CHS 828 resulted in tumor regression (final tumor volume compared to starting volume) after $10(-81 \%$; p < 0.0001) and 30 days $(-98 \%$; p < $0.0001)$. A detailed summary of tumor data is provided in Additional file 1 (see Additional file 1: Observation parameters of tumor-bearing SCID mice during the experiment).

In addition to the reduction in tumor volume, treatment with CHS 828 for 10 days also significantly reduced the percentage of viable tumor tissue from $75.5 \%$ to $15.4 \%$ (p $<0.0001$ ) and increased the fraction of dead (i.e. TUNEL positive) cells from $26.8 \%$ to $78.2 \%$ ( $p<0.0001$ ). The fraction of apoptotic cells was not different compared to controls when quantified by caspase-3 immunohistochemistry.

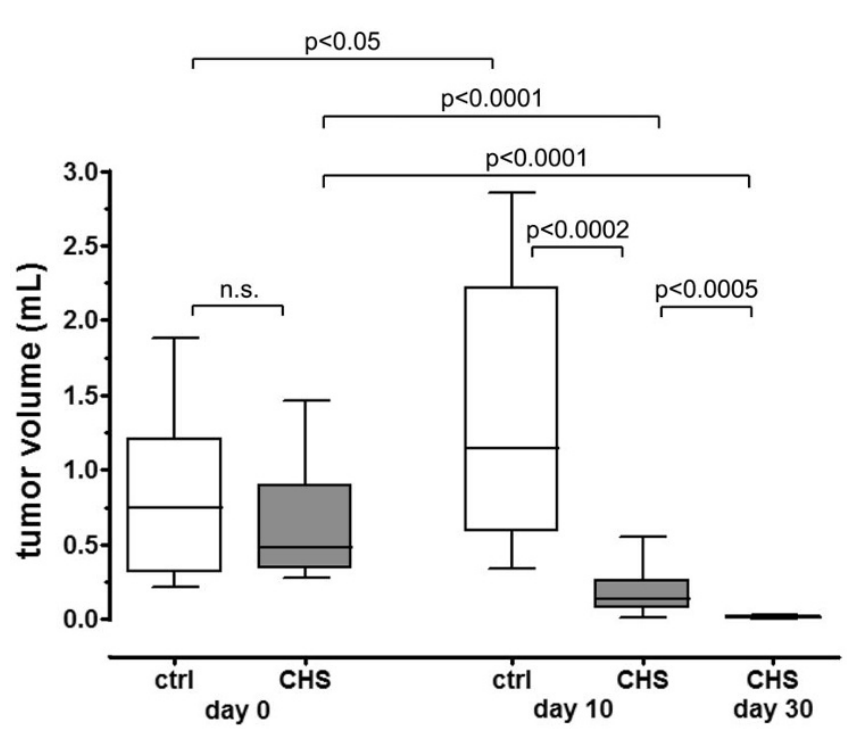

Figure 2

Orthotopic NB growth in SCID mice. SCID mice carrying orthotopic NB xenotransplants were randomized at an estimated tumor volume of $0.8 \mathrm{ml}(\mathrm{h} \mathrm{n}=10$, controls; $\mathrm{n} \mathrm{n}=$ 23, for CHS 828 treatment). After randomization, mice were treated daily with either vehicle $(\mathrm{h} n=9$; 10 days) or with CHS $828(20 \mathrm{mg} / \mathrm{kg}$; p.o.) for $10(\mathrm{n} \mathrm{n}=13)$ or $30(\mathrm{n} \mathrm{n}=10)$ days. Mann-Whitney $U$ test was used to evaluate differences between the groups.

There were no adverse effects of CHS 828 on the general status of the animals. CHS 828 did not affect the body or organ weight (liver, spleen, lung and kidney) in any of the treated animals compared with controls (see Additional file 2: Organ weight of healthy and tumor-bearing SCID mice). Furthermore, no treatment-related diarrhea or vomiting was observed, and the percentage of megakaryo-
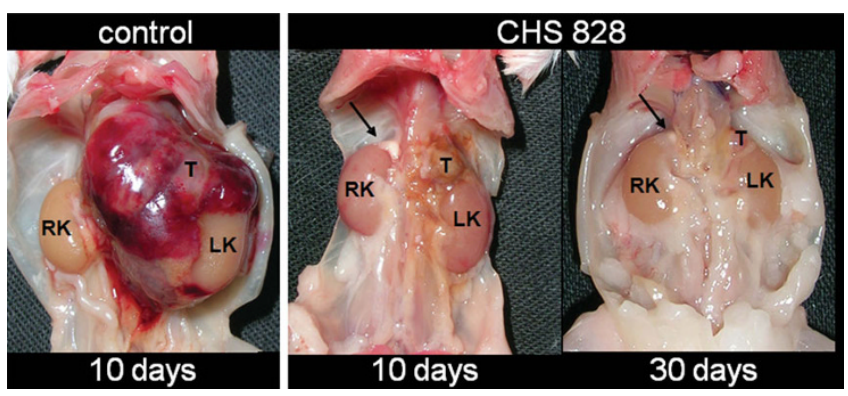

Figure 3

Orthotopic NB tumors at autopsy after treatment with CHS 828 or vehicle. Orthotopic tumors at autopsy treated with vehicle or CHS $828(20 \mathrm{mg} / \mathrm{kg} / \mathrm{day})$ for 10 or 30 days. Note the brown color of the tumor after 10 days of treatment, indicating areas of resorbed hemorrhage. $\mathrm{T}=$ tumor, RK = right kidney, LK = left kidney; arrows indicate the normal right adrenal gland. 
cytes in the bone marrow of the iliac crest did not differ between treated and healthy animals $(2.46 \% \pm 0.36 \%$ and $2.57 \% \pm 0.40 \%$, respectively; n.s.). Three mice were excluded from the study: 2 mice before ( 1 due to inexplicable weight loss and 1 due to paraplegia) and 1 mouse after randomization (paraplegia; control group). The 2 cases of paraplegia were caused by orthotopic NB growth extending into the spinal canal.

\section{Metastatic pattern of orthotopic NB mimics disseminated disease in high-risk NB patients}

Few large, macroscopic organ metastases were observed at autopsy. Examination of the lung, liver, spleen, bone marrow, and both kidneys under a dissection microscope revealed NB spread to many of these organs. This was confirmed by either hematoxylin-eosin staining or $\mathrm{CgA}$ immunohistochemistry. Table 2 summarizes NB spread in this orthotopic model compared to clinical NB.

The frequency of NB spread was reduced by CHS 828 compared with controls. Postmortem classification according to the INSS (International Neuroblastoma Staging System) showed that all control animals were classified as stage 4. Metastases detected in the treatment groups were smaller and showed morphological signs of regression (tumor necrosis) compared with metastases detected in controls (Figure 4).

In 2 control animals, there was NB growth in the thymus, thoracic lymph nodes, and along the thoracic vertebrae, whereas no NB spread to these sites could be detected in CHS 828-treated animals. Postmortem evaluation of treatment efficiency by applying the INSS revealed a trend toward lower stages (better resectability) when tumors were treated with CHS 828 (Table 3). No peritoneal metastases were detected, indicating that no free tumor cells were seeded onto the peritoneal surface during xenotransplantation.

Reduced CgA-levels in serum of CHS 828-treated animals Human CgA was detected in the serum of all vehicletreated controls $(n=9)(10.7 \pm 4.0 \mathrm{nmol} / \mathrm{L})$. However, in 10 days study with CHS 828 , only $1 / 13$ mice showed a detectable concentration of $\operatorname{CgA}(1 \mathrm{nM} / \mathrm{L})$, and no animals receiving long-term treatment $(n=10)$ or healthy littermates without tumors $(\mathrm{n}=5)$ had detectable $\mathrm{CgA}$ concentrations in serum (detection limit: $0.8 \mathrm{nmol} / \mathrm{L})(\mathrm{p}$ $<0.001)$.

\section{CHS 828 reduces tumor angiogenesis}

Daily administration of CHS 828 altered vascular parameters as determined by stereology (Table 4). Vessel density, vessel length density $\left(\mathrm{L}_{\mathrm{v}}\right)$, and surface density $\left(\mathrm{S}_{\mathrm{v}}\right)$ were significantly reduced in these tumors compared to vehicle-treated controls. The vessel volumetric density $\left(\mathrm{V}_{\mathrm{v}}\right)$ was reduced in CHS 828-treated tumors but the reduction was not significant $(\mathrm{p}=0.09)$ (Table 4$)$. A single layer of endothelial cells encircled the lumen of vessels in untreated tumors (Figure 5A and Figure 5C) whereas in CHS 828 treated tumors, endothelial cells were frequently not entirely surrounding the lumen (Figure 5B, D, E) or detaching from the basement membrane (Figure 5E). Despite the incomplete endothelial cell lining, only $1 / 13$ ( $8 \%$ ) of the animals treated with CHS 828 for 10 days showed intra-tumor hemorrhage, defined as erythrocytes outside vessel lumen, whereas $9 / 9(100 \%)$ of the tumors in control animals had erythrocytes in the tumor tissue.

Table 2: Invasive pattern of orthotopic NB in SCID mice

\begin{tabular}{|c|c|c|c|c|c|}
\hline & & \multicolumn{3}{|c|}{ Orthotopic mouse model } & \multirow{2}{*}{$\begin{array}{c}\text { Clinical NB } \\
{[28]}\end{array}$} \\
\hline \multicolumn{2}{|c|}{ Site } & $\begin{array}{l}\text { Control } \\
\text { at } 10 \text { days }\end{array}$ & $\begin{array}{l}\text { CHS } 828 \\
\text { at } 10 \text { days }\end{array}$ & $\begin{array}{l}\text { CHS } 828 \\
\text { at } 30 \text { days }\end{array}$ & \\
\hline \multicolumn{2}{|c|}{ Animals with metastases } & $100 \%(9 / 9)$ & $46 \%(6 / 13)^{*}$ & $40 \%(4 / 10)^{*}$ & \\
\hline \multicolumn{2}{|c|}{ Lung } & II\% (I/9) & $0 \%(0 / 13)$ & $0 \%(0 / 10)$ & $34 \%$ \\
\hline \multicolumn{2}{|c|}{ Liver } & $78 \%$ (7/9) & $23 \%(3 / 13)^{*}$ & $0 \%(0 / 10)^{* * *}$ & $30 \%$ \\
\hline \multicolumn{2}{|c|}{ Spleen } & $22 \%(2 / 9)$ & $8 \%(1 / 13)$ & $30 \%(3 / 10)$ & n.d. \\
\hline Bone marrow & $\begin{array}{l}\text { iliac crest } \\
\text { spine }^{\mathrm{a}}\end{array}$ & $\begin{array}{l}78 \%(7 / 9) \\
22 \%(2 / 9)\end{array}$ & $\begin{array}{c}23 \%(3 / 13)^{*} \\
8 \%(1 / 13)\end{array}$ & $\begin{array}{c}10 \%(1 / 10)^{* *} \\
10 \%(1 / 10)\end{array}$ & $71 \%$ \\
\hline \multicolumn{2}{|c|}{ Bone } & n.d. & n.d. & n.d. & $56 \%$ \\
\hline \multicolumn{2}{|c|}{ Lymph nodes } & n.d. & n.d. & n.d. & $31 \%$ \\
\hline \multicolumn{2}{|c|}{ Kidney invasiont } & $22 \%(2 / 9)$ & $0 \%(0 / 13)$ & $0 \%(0 / 10)$ & n.d. \\
\hline
\end{tabular}

Metastatic spread in SCID mice carrying orthotopic NB xenotransplants treated either with CHS 828 (20 mg/kg/day) or vehicle compared to metastatic incidence of NB at INSS stages 4 and 4S in clinic [28]. Data shows microscopic metastases in the marrow of the iliac crest, and composite data of macro- and microscopic metastases to the organs.

$*<0.05$; $* *<0.01$; $* * *<0.001$ (compared with controls); Fisher's exact test.

aNB cells in the spine and kidney were regarded as continuous tumor growth.

n.d., not determined; NB, neuroblastoma; INSS, International Neuroblastoma Staging System 

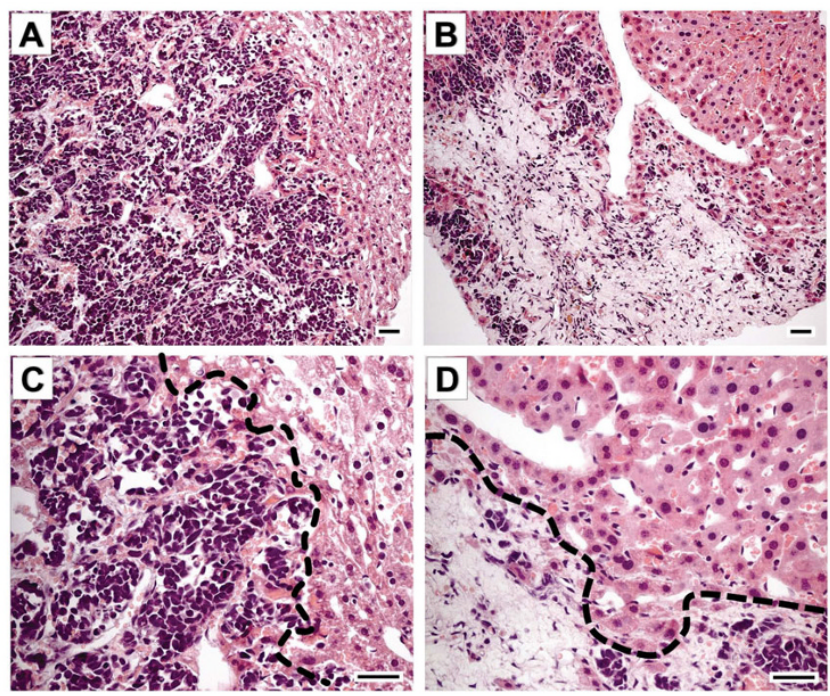

Figure 4

Metastatic NB growth in the liver. Liver metastases were smaller and exhibited large necrotic areas after 10 days of CHS 828 treatment (B) compared to controls (A). "C" and "D" are magnifications of "A" and "B", respectively. In C and $\mathbf{D}$ the border between healthy liver tissue and either viable tumor tissue (densely packed nuclei with sparse cytoplasm) (C) or areas of tumor necrosis (D) is outlined. Hematoxylin-eosin staining; bars $=20 \mu \mathrm{m}$.

\section{Discussion}

In this study, we developed an orthotopic model for highrisk NB and characterized tumor spread in this model. Our results showed that orthotopic implantation of MYCN amplified NB cells into the adrenal gland favors metastatic spread since all the control animals developed macroscopic metastasis. Postmortem NB staging according to the INSS criteria was performed to address the met-

Table 3: Staging of orthotopic NB in SCID mice

\begin{tabular}{ccccc}
\hline & \multicolumn{3}{c}{ Orthotopic mouse model } \\
\hline & $\begin{array}{c}\text { Control } \\
\text { at I0 days }\end{array}$ & $\begin{array}{c}\text { CHS 828 } \\
\text { at I0 days }\end{array}$ & $\begin{array}{c}\text { CHS 828 } \\
\text { at 30 days }\end{array}$ \\
\hline INSS & stage I & $0 \%(0 / 9)$ & $46 \%(6 / 13)$ & $60 \%(6 / 10)$ \\
& stage 2a & $0 \%(0 / 9)$ & $8 \%(1 / 13)$ & $0 \%(0 / 10)$ \\
& stage 3 & $0 \%(0 / 9)$ & $0 \%(0 / 13)$ & $0 \%(0 / 10)$ \\
& stage 4b & $100 \%(9 / 9)$ & $46 \%(6 / 13)$ & $40 \%(4 / 10)$ \\
\hline
\end{tabular}

Postmortem classification of control and CHS 828-treated animals using the INSS criteria for staging [27].

aNo extensive lymph node investigation was performed; therefore, "stage 2" was not divided into "2A" and "2B"

bINSS stage 4 was not separated into stages 4 and $4 S$ since $4 S$ is for infants

INSS (International Neuroblastoma Staging System) according to

Simpson and Gaze [27] at autopsy astatic pattern of NB [27]; the result showed that the metastatic pattern of MYCN-amplified NB cells in this model resembled high-risk NB. However, we observed a higher incidence of liver metastases in our model as compared to children with INSS stage 4 and older than 1 year. A possible explanation is the MYCN amplification status of the NB cells (IMR-32) used for orthotopic xenotransplantation in this study. MYCN amplification in NB increases risk for tumor spread to the liver, which in turn significantly decreases 3 year event-free survival in the patient group of INSS stage 4 and age over 1 year [28].

Using this orthotopic model for high-risk NB, we examined the effect of daily administration of the cyanoguanidine CHS 828 (20 mg/kg/day; equal to $60 \mathrm{mg} / \mathrm{m}^{2} /$ day) on the growth and metastatic potential of this highly malignant neuroendocrine tumor. The dose chosen is considered low since the lethal dose mice has been shown to be $853 \mathrm{mg} / \mathrm{m}^{2}$ and MTD in phase I studies was $228 \mathrm{mg} / \mathrm{m}^{2}$ [18]. The dose is also lower when compared to another preclinical study where CHS 828 was administered to mice at $100 \mathrm{mg} / \mathrm{kg} /$ week (300 mg/m²/week) and $250 \mathrm{mg} /$ $\mathrm{kg} /$ week (750 mg/m²/week) (designated "low" and "high" dose, respectively) [14]. Interestingly, the $300 \mathrm{mg} /$ $\mathrm{m}^{2} /$ week dose only reduced neuroendocrine tumor growth.

In our study we showed that CHS 828 induced tumor regression, reduced the viable tumor tissue fraction, and reduced the number of animals with metastases and number of metastases per animal without causing toxicity. This finding is of considerable importance since CHS 828 successfully treated large, established tumors that were more than twice the size of s.c. tumors in the study of Svensson et al. [17]. Additionally, we observed tumor regression whereas s.c. tumors showed reduced growth compared to controls [17]. The more pronounced treatment efficacy in the metastatic model mimicking clinical disseminated disease compared to heterotopic, s.c. models indicates that orthotopic models should be considered in preclinical drug screening programs.

Postmortem staging of treated animals showed a trend toward lower INSS stages compared to controls. In addition to tumor staging, we investigated the potential value of $\mathrm{CgA}$ serum levels for predicting treatment outcome. $\mathrm{CgA}$ is an acidic, monomeric protein and is co-stored and co-released with catecholamines from secretory granules in neural, endocrine, and neuroendocrine cells [29]. CgA was almost exclusively detected in serum from INSS stage 4 mice. Thus, our results support the concept of $\mathrm{NB}$ as a neuroendocrine tumor and the suitability of $\mathrm{CgA}$ as a NB tumor marker [30-32] and as an indicator of treatment efficacy. 
Table 4: Quantification of tumor angiogenesis by stereology

\begin{tabular}{|c|c|c|c|c|c|}
\hline & & $\begin{array}{l}\text { vessel density } \\
\left(\mathrm{mm}^{-2}\right)\end{array}$ & $\begin{array}{c}\mathbf{L v} \\
\left(\mathrm{mm}^{-2}\right)\end{array}$ & $\begin{array}{l}\mathbf{V} \mathbf{v} \\
\left(10^{-3}\right)\end{array}$ & $\begin{array}{c}\mathbf{S v} \\
\left(\mathrm{mm}^{-1}\right)\end{array}$ \\
\hline control $(n=9)$ & & $39.9 \pm 18.5$ & $77.2 \pm 37.1$ & $5.1 \pm 2.5$ & $2.6 \pm 1.3$ \\
\hline CHS 828a $(n=13)$ & & $12.8 \pm 10.3$ & $25.6 \pm 20.5$ & $2.8 \pm 2.1$ & $1.0 \pm 0.7$ \\
\hline & Changeb(\%) & $-67.1 \% * *$ & $-67.1 \% * *$ & $-44.7 \%$ & $-62.7 \% *$ \\
\hline
\end{tabular}

CHS 828 was administered at $20 \mathrm{mg} / \mathrm{kg} /$ day by oral gavage.

$\mathrm{Lv}$, length of vessels per tumor volume (length density); $\mathrm{Vv}$, volume of vessels per tumor volume (volumetric density); Sv, surface area of vessels per tumor volume (surface density). Mean \pm ISD, Mann-Whitney $U$ test.

${ }^{a} \mathrm{CHS} 828$ treatment for 10 days

bChange compared to control

$* p<0.05 * * p<0.01$

Immunohistological studies of tumor sections showed morphological signs of cell death, i.e. condensed and fragmented nuclei, after CHS 828 treatment for 10 days, causing a reduction of the viable tumor fraction by more than a factor of 5.7 compared to controls. The decrease in viable tissue fraction was independent of activated caspases3. This observation is supported by studies reporting that CHS 828 induces late programmed cell death with features not related to classical apoptosis [33,34]. In fact, CHS 828 has been reported to inhibit cellular synthesis of NAD resulting in energy depletion, and subsequent cell death [12]. NAD is produced primarily through biochemical salvage pathway using nicotinamide as a substrate. CHS 828 inhibits NAD synthesis from nicotinamide only after continuous and long time exposure [12]. Delayed cell death was confirmed in our in vitro studies in which the viability of human NB cells (IMR-32, SK-N-SH and SH-SY5Y) was affected only after prolonged exposure to CHS 828.

CHS 828 caused cell death in all three NB cell lines in vitro with $\mathrm{IC}_{50}$ values $20 \times$ below values of endothelial cells. Human fibroblasts never reached $\mathrm{IC}_{50}$ values at concentrations tested $(0.1 \mathrm{nM}-10 \mu \mathrm{M})$.

Compared to results from Åleskog et al. who tested CHS 828 toxicity on human lymphocytes in the same FMCA protocol described here, NB cells in our study had lower $\mathrm{IC}_{50}$ values [35]. This indicates a higher drug sensitivity of NB cells. We speculate that the high CHS 828 sensitivity of the NB cell lines might be due to an active uptake of CHS 828 in NB cells, mediated by the noradrenalin transport transmembrane protein in analogy with MIBG [36]. It has been shown that the human NB cells used in this study are so-called MIBG-positive cell lines (a characteristic shared with $85 \%$ of NB cells in patients) in which there is an apparent noradrenalin transporter gene expression $[37,38]$. MIBG is a molecule that is specifically taken up by most NB cells [39] and cytotoxic drugs with structural homology to MIBG (e.g. CHS 828) may have a similar selectively for NB cells. To address the question whether
CHS 828 was less active in cell lines with greater avidity for MIBG, we included the NB cell line SK-N-SH in our in vitro toxicity studies. CHS caused cell death in all NB cell lines without any correlation to their avidity in taking up MIBG. We therefore conclude that CHS 828 could be taken up by different NB cells despite presence of chlorophenoxyhexyl and cyano groups in the chemical structure of this drug.

As rodents have been shown to tolerate higher CHS 828 levels than man both in vitro [40] and in vivo [41], the dose chosen in the current study can be considered low for the host cells (including the endothelial cells) but higher for the human tumor cells. Despite this, both tumor vessels of murine origin and human tumor cells were affected by treatment with CHS 828. Thus, we believe that the current administration of CHS 828 represents a dual targeting approach involving the inhibition of angiogenesis, and direct tumor cell toxicity. The two processes (angiogenesis inhibition and tumor cell toxicity) may have different kinetics and may vary in proportion with the distance from the nearest vessel. Furthermore, treated animals showed less intra-tumor hemorrhage than controls. Therefore, the vasculature in tumors treated with CHS 828 was more stable than vessels in rapidly growing, untreated tumors indicating vessel normalization [42].

More prolonged schedules of CHS 828 have previously been shown to increase antitumor activity as well as toxicity in vitro [13], in vivo [41] and clinically $[18,19]$. In the current study, no bone marrow toxicity due to prolonged exposure to low doses of CHS 828 was found. This was investigated by quantifying the percentage of megakaryocytes in the bone marrow of the iliac crest. Megakaryocytes, the precursors of platelets, were easily identified despite the disorderly arranged cells in the bone marrow. We found that the frequency of megakaryocytes in the bone marrow was not affected by CHS 828 treatment.

In clinical phase I studies, CHS 828 showed a large variation in drug uptake both between and within patients 

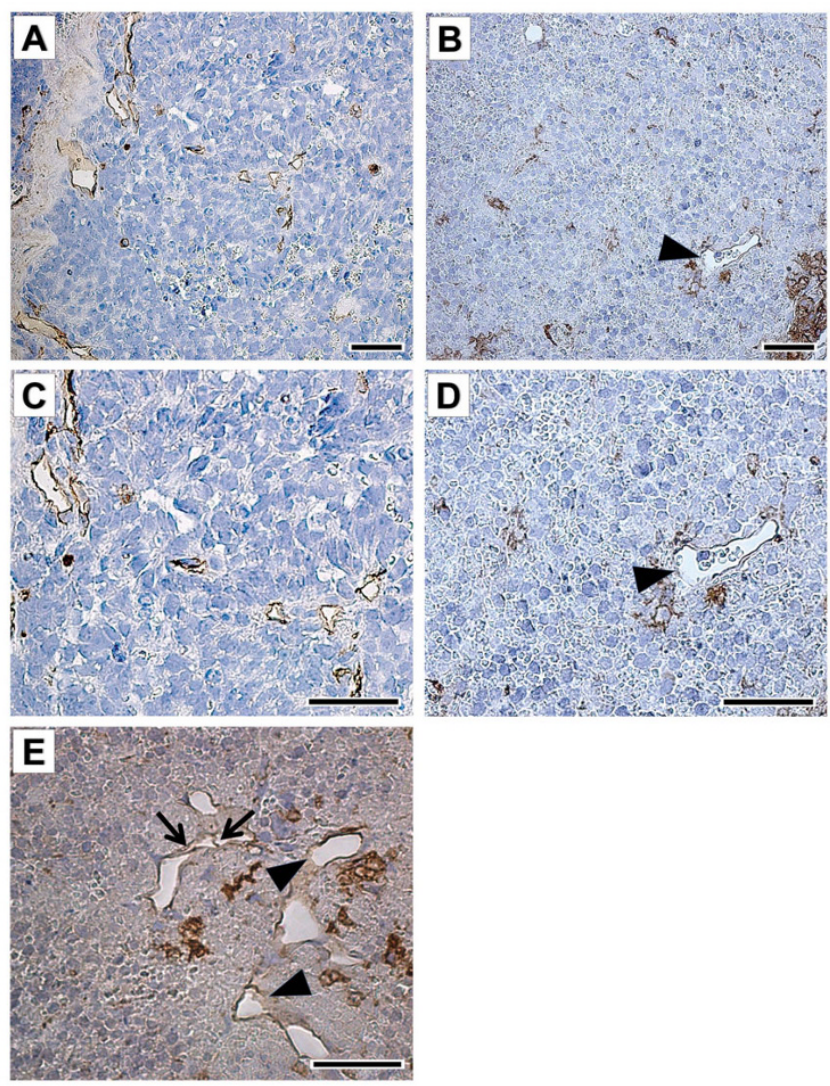

Figure 5

Representative morphology and vessel profile in orthotopic NB xenografts. Vehicle-treated tumors (control) contained a larger number of small vessels (stained in brown) (A, C) compared to CHS 828 (20 mg/kg/day; p.o.) treated tumors (B, D-E) already 10 days after randomization. Vessels of control tumors had a thin endothelial cell lining (brown) $(\mathbf{A}, \mathbf{C})$. CHS 828 treated tumors revealed vessels only partly surrounded by endothelial cells (arrowheads) (B, D-E) or endothelial cells detaching from the basement membrane (arrows) (E). $\mathbf{C}$ and $\mathbf{D}$ are magnifications of $\mathbf{A}$ and $\mathbf{B}$, respectively. Bandeiraea simplicifolia-I (BS-I) lectin staining (brown); bar $=40 \mu \mathrm{m}$.

$[18,19]$ which was also observed in a previous study in nude mice [17]. This inter-individual variability has partly been explained by variations of hepatic and intestinal CYP3A4 activity, an enzyme important for metabolizing cyanoguanidines such as CHS $828[19,43]$. Another explanation for this variability might be related to the low solubility of CHS 828 hampering uptake in the gastrointestinal tract. Clinical trials using orally administered CHS 828 were discontinued due to the variation in exposure levels and dose limiting toxicities. Hence a water soluble prodrug, EB1627 (GMX1777) was synthesized by adding a tetraethylenglycol moiety to the parent drug CHS 828 (GMX1778). This compound could be administered i.v. thus allowing a controlled dosing to the patient. After intravenous administration, the tetraethylenglycol moiety rapidly dissociates and releases CHS 828 without reducing antitumor activity [44].

\section{Conclusion}

We believe that the metastatic and clinically relevant model evaluated here provides an excellent tool for examining new treatment strategies in children with high-risk NB. Based on data derived from this model, we suggest that the active compound CHS 828 might provide clinical benefits in treating children with high-risk NB.

\section{Competing interests}

The authors declare that they have no competing interests.

\section{Authors' contributions}

DF, RC and FA designed the study. DF acquired data which was analyzed by DF and FA, except for CgA data which was analyzed by MS. RC contributed with data interpretation and drafting of the manuscript written by DF and FA. EL and MS provided input in writing of the manuscript. All authors read and approved the manuscript.

\section{Additional material}

\section{Additional File 1}

Observation parameters of tumor-bearing SCID mice during the experiment. A table summarizing individual follow-up of body weight and tumor development for each individual mouse in the study. Statistical analysis (Mann-Whitney $\mathrm{U}$ test) indicates group differences in tumor volume, tumor weight and tumor index (tumor weight/final body weight $\mathrm{x}$ 100).

Click here for file

[http://www.biomedcentral.com/content/supplementary/14795876-7-16-S1.doc]

\section{Additional File 2}

Organ weight of healthy and tumor-bearing SCID mice. A table summarizing organ weight for each individual mouse in the study, including healthy littermates. Statistical analysis (Kruskal Wallis test).

Click here for file

[http://www.biomedcentral.com/content/supplementary/14795876-7-16-S2.doc]

\section{Acknowledgements}

Barbro Einarsson provided excellent technical assistance. CHS 828 was kindly provided by LEO Pharma (Ballerup, Denmark). This work was supported by a grant from the Children's Cancer Foundation of Sweden and the Gillbergska Foundation.

\section{References}

I. Cotterill SJ, Pearson AD, Pritchard J, Foot AB, Roald B, Kohler JA, Imeson J: Clinical prognostic factors in 1277 patients with neuroblastoma: results of The European Neuroblastoma Study Group 'Survey' 1982-1992. Eur J Cancer 2000, 36:901-908. 
2. De Bernardi B, Nicolas B, Boni L, Indolfi P, Carli M, Cordero Di Montezemolo L, Donfrancesco A, Pession A, Provenzi M, di Cataldo A, et al.: Disseminated neuroblastoma in children older than one year at diagnosis: comparable results with three consecutive high-dose protocols adopted by the Italian Co-Operative Group for Neuroblastoma. J Clin Oncol 2003, 2 I: I592-I601.

3. Meitar D, Crawford SE, Rademaker AW, Cohn SL: Tumor angiogenesis correlates with metastatic disease, $\mathbf{N}$-myc amplification, and poor outcome in human neuroblastoma. J Clin Oncol 1996, I 4:405-4|4.

4. Peddinti R, Zeine R, Luca D, Seshadri R, Chlenski A, Cole K, Pawel B, Salwen HR, Maris JM, Cohn SL: Prominent microvascular proliferation in clinically aggressive neuroblastoma. Clin Cancer Res 2007, I 3:3499-3506.

5. Backman U, Svensson A, Christofferson R: Importance of vascular endothelial growth factor $A$ in the progression of experimental neuroblastoma. Angiogenesis 2002, 5:267-274.

6. Segerstrom L, Fuchs D, Backman U, Holmquist K, Christofferson R, Azarbayjani F: The Anti-VEGF Antibody Bevacizumab Potently Reduces the Growth Rate of High-Risk Neuroblastoma Xenografts. Pediatr Res 2006, 60:576-58I.

7. Kerbel RS: Antiangiogenic therapy: a universal chemosensitization strategy for cancer? Science 2006, 3 I 2: I I 7 I- I I75.

8. Bertolini F, Paul S, Mancuso P, Monestiroli S, Gobbi A, Shaked Y, Kerbel RS: Maximum tolerable dose and low-dose metronomic chemotherapy have opposite effects on the mobilization and viability of circulating endothelial progenitor cells. Cancer Res 2003, 63:4342-4346.

9. Pietras K, Hanahan D: A multitargeted, metronomic, and maximum-tolerated dose "chemo-switch" regimen is antiangiogenic, producing objective responses and survival benefit in a mouse model of cancer. J Clin Oncol 2005, 23:939-952.

10. Klement G, Baruchel S, Rak J, Man S, Clark K, Hicklin DJ, Bohlen P, Kerbel RS: Continuous low-dose therapy with vinblastine and VEGF receptor-2 antibody induces sustained tumor regression without overt toxicity. J Clin Invest 2000, I 05:R I5-24.

II. Kerbel RS, Kamen BA: The anti-angiogenic basis of metronomic chemotherapy. Nat Rev Cancer 2004, 4:423-436.

12. Olesen $U H$, Christensen $M K$, Bjorkling $F$, Jaattela $M$, Jensen $P B$, Sehested M, Nielsen SJ: Anticancer agent CHS-828 inhibits cellular synthesis of NAD. Biochem Biophys Res Commun 2008, 367:799-804.

13. Hassan SB, Jonsson E, Larsson R, Karlsson MO: Model for time dependency of cytotoxic effect of CHS 828 in vitro suggests two different mechanisms of action. J Pharmacol Exp Ther 200I, 299: I|40-I| 47.

14. Johanson V, Arvidsson Y, Kolby L, Bernhardt P, Sward C, Nilsson O, Ahlman $\mathrm{H}$ : Antitumoural effects of the pyridyl cyanoguanidine CHS 828 on three different types of neuroendocrine tumours xenografted to nude mice. Neuroendocrinology 2005, 82: $17 \mid-176$.

15. Hovstadius $P$, Lindhagen $E$, Hassan S, Nilsson K, Jernberg-Wiklund $H$, Nygren $\mathrm{P}$, Binderup L, Larsson R: Cytotoxic effect in vivo and in vitro of CHS 828 on human myeloma cell lines. Anticancer Drugs 2004, I 5:63-70.

16. Hjarnaa PJ, Jonsson E, Latini S, Dhar S, Larsson R, Bramm E, Skov T, Binderup L: CHS 828, a novel pyridyl cyanoguanidine with potent antitumor activity in vitro and in vivo. Cancer Res 1999, 59:575I-5757

17. Svensson A, Backman U, Jonsson E, Larsson R, Christofferson R: CHS 828 inhibits neuroblastoma growth in mice alone and in combination with antiangiogenic drugs. Pediatr Res 2002, 5 I:607-6II.

18. Ravaud A, Cerny T, Terret C, Wanders J, Bui BN, Hess D, Droz JP, Fumoleau P, Twelves C: Phase I study and pharmacokinetic of CHS-828, a guanidino-containing compound, administered orally as a single dose every 3 weeks in solid tumours: An ECSG/EORTC study. Eur J Cancer 2005, 4I:702-707.

19. Hovstadius P, Larsson R, Jonsson E, Skov T, Kissmeyer AM, Krasilnikoff K, Bergh J, Karlsson MO, Lonnebo A, Ahlgren J: A Phase I study of CHS 828 in patients with solid tumor malignancy. Clin Cancer Res 2002, 8:2843-2850.

20. Zaizen $Y$, Taniguchi S, Suita S: The role of cellular motility in the invasion of human neuroblastoma cells with or without $\mathbf{N}$ myc amplification and expression. J Pediatr Surg 1998, 33:1765- 1770 .
21. Biedler JL, Roffler-Tarlov S, Schachner M, Freedman LS: Multiple neurotransmitter synthesis by human neuroblastoma cell lines and clones. Cancer Res 1978, 38:375I-3757.

22. Veitonmaki N, Fuxe J, Hultdin M, Roos G, Pettersson RF, Cao Y: Immortalization of bovine capillary endothelial cells by hTERT alone involves inactivation of endogenous p I 6INK4A/pRb. Faseb J 2003, I 7:764-766.

23. Larsson R, Nygren P, Ekberg M, Slater L: Chemotherapeutic drug sensitivity testing of human leukemia cells in vitro using a semiautomated fluorometric assay. Leukemia 1990, 4:567-57I.

24. Welsh N: Assessment of apoptosis and necrosis in isolated islets of Langerhans: methological considerations. Curr Top Biochem Res 2000, 3:189-200.

25. Backman U, Christofferson $R$ : The selective class III/V receptor tyrosine kinase inhibitor SUI I 657 inhibits tumor growth and angiogenesis in experimental neuroblastomas grown in mice. Pediatr Res 2005, 57:690-695.

26. Wassberg E, Hedborg F, Skoldenberg E, Stridsberg M, Christofferson $\mathrm{R}$ : Inhibition of angiogenesis induces chromaffin differentiation and apoptosis in neuroblastoma. Am J Pathol 1999, I 54:395-403.

27. Simpson JK, Gaze MN: Current Management of Neuroblastoma. Oncologist 1998, 3:253-262.

28. DuBois SG, Kalika Y, Lukens JN, Brodeur GM, Seeger RC, Atkinson JB, Haase GM, Black CT, Perez C, Shimada H, et al.: Metastatic sites in stage IV and IVS neuroblastoma correlate with age, tumor biology, and survival. J Pediatr Hematol Oncol 1999, 2 I: I8I-I89.

29. Hendy GN, Bevan S, Mattei MG, Mouland AJ: Chromogranin A. Clin Invest Med 1995, 1 8:47-65.

30. Hsiao RJ, Seeger RC, Yu AL, O'Connor DT: Chromogranin A in children with neuroblastoma. Serum concentration parallels disease stage and predicts survival. J Clin Invest 1990, 85: $1555-1559$.

31. Wassberg E, Stridsberg M, Christofferson R: Plasma levels of chromogranin $A$ are directly proportional to tumour burden in neuroblastoma. J Endocrinol 1996, I 5 I:225-230.

32. Seregni E, Ferrari L, Bajetta E, Martinetti A, Bombardieri E: Clinica significance of blood chromogranin A measurement in neuroendocrine tumours. Ann Oncol 200I, I 2(Suppl 2):S69-72.

33. Frost BM, Lonnerholm G, Nygren P, Larsson R, Lindhagen E: In vitro activity of the novel cytotoxic agent CHS 828 in childhood acute leukemia. Anticancer Drugs 2002, 13:735-742.

34. Martinsson $P$, Liminga $G$, Dhar $S$, de la Torre $M$, Lukinius $A$, Jonsson E, Bashir Hassan S, Binderup L, Kristensen J, Larsson R: Temporal effects of the novel antitumour pyridyl cyanoguanidine (CHS 828) on human lymphoma cells. Eur J Cancer 200I, 37:260-267.

35. Aleskog A, Bashir-Hassan S, Hovstadius P, Kristensen J, Hoglund M, Tholander B, Binderup L, Larsson R, Jonsson E: Activity of CHS $\mathbf{8 2 8}$ in primary cultures of human hematological and solid tumors in vitro. Anticancer Drugs 200 I, I 2:821-827.

36. Montaldo PG, Lanciotti M, Casalaro A, Cornaglia-Ferraris P, Ponzon $M$ : Accumulation of $\mathbf{m}$-iodobenzylguanidine by neuroblastoma cells results from independent uptake and storage mechanisms. Cancer Res 1991, 5 I:4342-4346.

37. Boyd M, Cunningham SH, Brown MM, Mairs RJ, Wheldon TE: Noradrenaline transporter gene transfer for radiation cell kill by 13 II meta-iodobenzylguanidine. Gene Ther 1999, 6: $1147-1152$

38. Lode HN, Bruchelt G, Seitz G, Gebhardt S, Gekeler V, Niethammer $D$, Beck J: Reverse transcriptase-polymerase chain reaction (RT-PCR) analysis of monoamine transporters in neuroblastoma cell lines: correlations to meta-iodobenzylguanidine (MIBG) uptake and tyrosine hydroxylase gene expression. Eur J Cancer | 995, 3 | A:586-590.

39. Kushner $\mathrm{BH}$ : Neuroblastoma: a disease requiring a multitude of imaging studies. J Nucl Med 2004, 45: I I 72-I I 88.

40. Lindhagen E, Hjarnaa PJ, Friberg LE, Latini S, Larsson R: Pharmacodynamic differences between species exemplified by the novel anticancer agent CHS 828. Drug Dev Res 2004, 61:218-226.

41. Friberg LE, Hassan SB, Lindhagen E, Larsson R, Karlsson MO: Pharmacokinetic-pharmacodynamic modelling of the scheduledependent effect of the anti-cancer agent CHS 828 in a rat hollow fibre model. Eur J Pharm Sci 2005, 25: I63-I73.

42. Jain RK: Normalization of tumor vasculature: an emerging concept in antiangiogenic therapy. Science 2005, 307:58-62. 
43. Lown KS, Kolars JC, Thummel KE, Barnett JL, Kunze KL, Wrighton SA, Watkins PB: Interpatient heterogeneity in expression of CYP3A4 and CYP3A5 in small bowel. Lack of prediction by the erythromycin breath test. Drug Metab Dispos 1994, 22:947-955.

44. Binderup E, Bjorkling F, Hjarnaa PV, Latini S, Baltzer B, Carlsen M, Binderup L: EB 1627: a soluble prodrug of the potent anticancer cyanoguanidine CHS828. Bioorg Med Chem Lett 2005, | 5:249|-2494.

Publish with Bio Med Central and every scientist can read your work free of charge

"BioMed Central will be the most significant development for disseminating the results of biomedical research in our lifetime. " Sir Paul Nurse, Cancer Research UK

Your research papers will be:

- available free of charge to the entire biomedical community

- peer reviewed and published immediately upon acceptance

- cited in PubMed and archived on PubMed Central

- yours - you keep the copyright

Submit your manuscript here:

http://www.biomedcentral.com/info/publishing_adv.asp
BiolMedcentral 